\title{
Publisher's Note
}

๑) Springer Nature B.V. 2019

We are very happy to introduce the new Editor-in-Chief Professor Harsh K. Gupta (National Geophysical Research Institute, Hyderabad, India) to our readers. He will replace Dr. V. Schenk as Editor-in-Chief. Professor Harsh K. Gupta will be working in close collaboration with the Editors-in-Chief Professor Thomas Glade and Professor James Goff. It is with immense gratitude that we thank Dr. Schenk for the many years of service to the journal and the numerous invaluable contributions made to the success of the journal.

Publisher's Note Springer Nature remains neutral with regard to jurisdictional claims in published maps and institutional affiliations. 